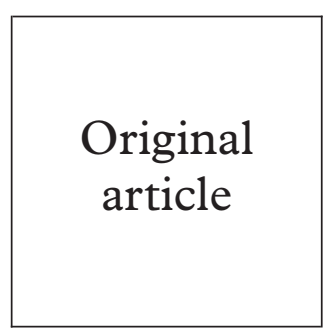

\title{
Highlights of the sexual activity of the heterosexual population in the province of Quebec
}

\author{
M Brisson, M-C Boily, B R Mâsse, A Adrien, V Léaune
}

Objectives: To describe and quantify the level of sexual activity of the heterosexually active population of Quebec.

Methods: The data analysed included 2889 heterosexually active individuals aged 15-60 $\left(\mathrm{age}_{\text {med }}=32\right)$ from a 1996-7 survey on the sexual lifestyles of the general population of Quebec. Various probability distributions were studied to assess their capacity to describe and quantify the lifetime and yearly numbers of sexual partners of the sampled population. To estimate the annual rates of new partner acquisition, a generalised linear model was fitted to the number of lifetime sexual partners as a function of age, years of sexual activity, and sex.

Results: The mean and variance of the number of lifetime sexual partners for men $(\overline{\mathrm{x}}=11$, $\left.\mathrm{s}^{2}=163\right)$ is higher than for women $\left(\overline{\mathrm{x}}=6, \mathrm{~s}^{2}=72\right)$. The negative binomial and lognormal probability distributions give the most adequate fit to the lifetime number of partners for both agglomerated and stratified (by sex and age) data. The estimated annual rates of new partner acquisition provide two important results for prevention: (1) the first year of sexual activity represents the highest annual rate of new partner acquisition independent of age, (2) annual rates of new partner acquisitions increase through mid-life (ages 40-50) combined with a decrease in condom use. Conclusion: Problems caused by the use of large categories in the estimation of mean and variance cannot totally be overcome by fitting probability distributions to the empirical data despite good fits. Furthermore, we believe that adequate estimates of the annual rate of new partner acquisition should be a better measure of the risk of HIV infection than the number of partners since the first is a measure of incidence while the second is a measure of prevalence.

(Sex Transm Inf 1999;75:296-299)

Keywords: sexual activity; heterosexual population; Quebec

\section{Introduction}

Recently, many countries have embarked on large scale sexual behaviour surveys. ${ }^{1-3}$ Despite their indisputable importance, they often encompass limitations that can dilute the information, hinder comparisons, and limit their use for modellers. For example, the mean number of partnerships reported by men far exceeds that reported by women (should be equal when the male:female ratio $=1: 1)$, the heterogeneity in sexual activity is underestimated, the number of sexual partners per time unit is used instead of new partners (as required by models) to quantify sexual activity, data are collected/reported in few, large, unbound categories (for example, $>10$ ).$^{4-6}$

In this paper, we describe and quantify the sexual activity of the heterosexual population of the province of Quebec by fitting an appropriate probability distribution and estimating annual rates of partner acquisition to lifetime sexual partners data. Problems posed by large categories are illustrated and interesting patterns of sexual behaviour revealed.

\section{Methods}

The data were obtained from the 1996-7 survey on the sexual lifestyles of the general population of Quebec (simple random sample of 3501 individuals). ${ }^{7}$ Our analysis is restricted to sexually active heterosexuals, aged 15-60 years old ( $82.5 \%$ of the initial sample), since those without any lifetime sexual partner do not contribute to sexually transmitted disease (STD) transmission.

To elude limitations posed by categorical data and facilitate mean (variance) estimates, different probability distributions were fitted to the empirical lifetime number of sexual partners distribution. Quality of fits were assessed with the $\rho$ statistic $\left(\rho=\left(\chi^{2} / n\right)\right.$, independent of $n$, $\rho<0.3$ indicates a good fit). ${ }^{8}$ The predicted current annual rates of partner acquisition, of an individual of sex $k$, age cohort $i$, and jth year of sexual activity, were estimated by first fitting a generalised linear model to the lifetime number of sexual partners $\left(Y_{\text {kij }}\right)$ as a function of age $\left(w_{\mathrm{i}}\right)$, number of years of sexual active life $\left(x_{\mathrm{j}}\right)$ and $\operatorname{sex}(z)\left(\hat{\mathrm{Y}}_{k i j}=\alpha_{\mathrm{i}} w_{\mathrm{i}}+\sum[\mathrm{j}]_{\mathrm{n}=0} \lambda_{\mathrm{n}} x_{\mathrm{n}}+\delta z+\right.$ $\varepsilon_{\mathrm{kij}} ; \varepsilon_{\mathrm{kji}} \sim$ negative binomial, link function: $\log$ $(\mu)) .{ }^{6} 8$ Data on age and sexually activity duration variables are in 5 years category. Thereafter, the predicted current annual rates $\left(\hat{R}_{k \mathrm{kj}}\right)$ of an individual of sex $\mathrm{k}$, age 1 , and jth year of sexual activity is: $\hat{\mathrm{R}}_{\mathrm{kj}}=\left(\hat{\mathrm{Y}}_{\mathrm{k} \mathrm{k}(\mathrm{i})}-\hat{\mathrm{Y}}_{\mathrm{ki}(\mathrm{j}-1)}\right) / 5$ years.

\section{Results}

Table 1 shows the distribution of the lifetime number of sexual partners for the heterosexual population of Quebec. A larger fraction of men than women have $0,>5$, and $>20$ lifetime partners but more women have 1-4 lifetime partners. The midpoint (see table 1 for details) mean (variance) lifetime number of partners for the sexually active population (excluding 0 ) of Quebec are 10.8 (162.3) and 6.2 (71.5) for males and females respectively compared with 
Table 1 Sexual behaviour of the sampled Quebec and British populations

\begin{tabular}{|c|c|c|c|c|c|c|c|c|c|}
\hline \multirow[b]{2}{*}{ No. of lifetime partners } & \multicolumn{4}{|l|}{ Quebec } & \multirow[b]{2}{*}{ No of lifetime partners } & \multicolumn{4}{|l|}{ Britain * } \\
\hline & $\begin{array}{l}\text { Men } \\
\text { number }\end{array}$ & $(\%)$ & $\begin{array}{l}\text { Women } \\
\text { number }\end{array}$ & $(\%)$ & & $\begin{array}{l}\text { Men } \\
\text { number }\end{array}$ & $(\%)$ & $\begin{array}{l}\text { Women } \\
\text { number }\end{array}$ & $(\%)$ \\
\hline Sexually inactive & & & & & Sexually inactive & & & & \\
\hline 0 & 94 & $(7.2)$ & 121 & $(6.7)$ & 0 & 553 & $(6.6)$ & 599 & $(5.7)$ \\
\hline Sexually active $\dagger$ & & & & & Sexually active $\dagger$ & & & & \\
\hline 1 & 212 & $(16.3)$ & 472 & $(26.2)$ & 1 & 1727 & $(20.6)$ & 4124 & $(39.3)$ \\
\hline 2 to 4 & 343 & $(26.3)$ & 616 & $(34.2)$ & 2 & 889 & $(10.6)$ & 1776 & $(16.9)$ \\
\hline 5 to 9 & 283 & $(21.7)$ & 329 & $(18.3)$ & 3 to 4 & 1543 & $(18.4)$ & 1913 & $(18.2)$ \\
\hline 10 to 19 & 196 & $(15.1)$ & 187 & $(10.4)$ & 5 to 9 & 1626 & $(19.4)$ & 1365 & $(13.0)$ \\
\hline $20+$ & 174 & (13.4) & 77 & $(4.3)$ & $10+$ & 2046 & $(24.4)$ & 714 & $(6.8)$ \\
\hline Total & 1302 & $(100.0)$ & 1802 & $(100.0)$ & Total & 8384 & $(100.0)$ & 10491 & $(100.0)$ \\
\hline & Mean & Variance & Mean & Variance & & Mean & Variance & Mean & Variance \\
\hline $\begin{array}{l}\text { Categorical data (midpoint } \\
\text { estimates) } \ddagger \S\end{array}$ & 10.8 & 162.6 & 6.2 & 71.5 & $\begin{array}{l}\text { Categorical data (midpoint } \\
\text { estimates) } \ddagger \llbracket \uparrow\end{array}$ & 7.8 & 56.9 & 3.9 & 24.2 \\
\hline $\begin{array}{l}\text { Discrete data (true sample } \\
\text { estimates) }\end{array}$ & NA & NA & NA & NA & $\begin{array}{l}\text { Discrete data (true sample } \\
\text { estimates) }\end{array}$ & 10.6 & 7031.9 & 3.6 & 174.8 \\
\hline Lognormal distribution & 14.8 & 1617.5 & 6.9 & 214.5 & Lognormal distribution $_{\check{c} \dot{c}}$ & 17.8 & 6905.3 & 4.1 & 43.6 \\
\hline Negative binomial $^{\star \star}$ & 9.4 & 119.6 & 5.3 & 35.4 & Negative binomialff & 7.4 & 70.8 & 2.4 & 7.9 \\
\hline
\end{tabular}

NA $=$ not available.

${ }^{\star}$ British National Survey of Sexual Attitudes and Lifestyles (ACSF Investigators ${ }^{3}$ ) $†$ Sexually active population $=$ those declaring $\geqslant 1$ lifetime sexual partners. $\ddagger$ The midpoint mean (variance) estimates are based on the mid-interval value for the first five categories. $\$$ For the $(20+)$ category of Quebec the mid-interval is fixed to the average number of annual partners (=40 lifetime partners). ๆ $\uparrow$ For Britain, the mid-interval value of the $(10+)$ category is fixed to 20 . Best fit variables values; for the

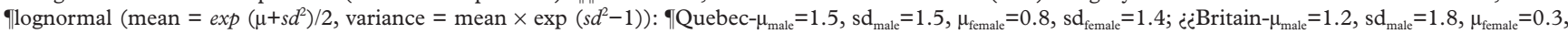
$\sigma_{\text {female }}=1.3$; for the negative binomial $($ mean $=\mathrm{k}(1-\mathrm{p}) / \mathrm{p}$, variance $=$ mean $/ \mathrm{p}):{ }^{\star \star} \mathrm{Quebec}-\mathrm{p}_{\text {male }}=0.07, \mathrm{k}_{\text {male }}=0.63, \mathrm{p}_{\text {female }}=0.12, \mathrm{k}_{\mathrm{female}}=0.58 ; f f B$ ritain- $\mathrm{p}_{\text {male }}=0.09, \mathrm{k}_{\text {male }}=0.53$, $\mathrm{p}_{\text {female }}=0.18, \mathrm{k}_{\text {female }}=0.31$.

those of France, ${ }^{3} 10.1(70.7)$ and $4.4(33.2)$; Britain, ${ }^{1} 7.8$ (56.9) and 3.9 (24.2); and the United States, ${ }^{2} 11.5(189.4)$ and $5.0(82.7)$. Male means and variances are approximately twice those of females. Discrepancies between sexes can be explained by differential recall or reporting biases, low response rates, undersampling of high risk groups, acquisition of partners abroad, and differential age mixing pattern. ${ }^{4-69}$ Differences in midpoint estimates between countries are difficult to interpret since they are based on arbitrary cut off points. Table 1 suggests that a similar proportion of males and females are sexually inactive in Quebec (men $7.2 \%(\mathrm{p}=0.40)$ and women $6.7 \%$ $(p=0.09))$ as in Britain (men 6.6\% $(p=0.40)$ and women $5.7 \%(\mathrm{p}=0.09))^{1}$ However, more sexually active British men and women (men $22.1 \%$ and women $41.7 \%$ ) ( $p<0.01$ ) have only one lifetime partner (Quebec: men 17.6\% and women $28.0 \%$ ) ( $\mathrm{p}<0.01$ ). Moreover, $30.6 \%$ $(15.7 \%)$ of men (women) in Quebec declared $>10$ lifetime partners compared with $26.1 \%$ ( $p$ $<0.01)(7.2 \%)^{4}$ in the United Kingdom. Our data share some qualitative characteristics with the French, ${ }^{3}$ British, ${ }^{1}$ and the American ${ }^{2}$ sex surveys. Many individuals have few partners and few individuals have many. Women over 40 years of age declare fewer partners than younger women. The mean and variance of sexual partners are larger for men than for women.

The best fits to the empirical age stratified and unstratified distributions of sexually active males and females were obtained with the negative binomial $(\rho=0.02-0.27)$ and the log normal $(\rho=0.04-0.25)$ and was poorer with the gamma $(\rho=0.16-0.78)$, the Poisson (because $\sigma^{2}=\mu$ ), and the normal (because symmetric) distributions. Although table 1 only presents overall moment (mean and variance) estimates for females and males, the analysis was also performed on 5 years age cohorts. Similar results were obtained. Fits were similar for the French, the British, the US data, and Kault's results. ${ }^{9}$ This suggests that a common family distribution could be appropriate to summarise concisely the empirical distribution. This should be validated for other populations with possibly different cultural partner acquisition processes (for example, Asians, Africans).

Table 1 shows the difference between the midpoint (categorical data), true sample (discrete data: Britain only), lognormal, and binomial overall female and male mean (variance) estimates for Quebec and Britain. The negative binomial tends to underestimate the midpoint mean and variance (except British males) and true sample ones. The lognormal overestimates the midpoint and true sample means and sometimes overestimates (some 5 years age cohorts; results not shown) or underestimates the true sample variance. Generally, the negative binomial estimates were closer to the true sample means while the sample variances were of similar magnitude than the lognormal estimates. Deceptively, despite high quality fits to categorical data, moment estimates based on distribution variables do not clearly indicate which distribution to choose.

Figure 1A shows that the current annual rates of partner acquisition as a function of years of sexual activity are very high during the first year of sexual activity since at least one partner is required to become sexually active. Immediately after the first year, a sharp decrease is observed and followed by a 4 year increase. Between the 5th and 15th year of sexual activity, there is a levelling of partner acquisition (stable relationships). Then from year 15, another increase (dissolutions) is observed. For a fixed sexual activity duration, the magnitude in sexual activity is lower for older individuals and for females, probably indicative of different age at sexual debut, sexual activity level, reporting biases by sex and age.

Figure 1B differentiates between three age specific measures (details in legend of fig 1B) of sexual activity: the annual number of partners, 

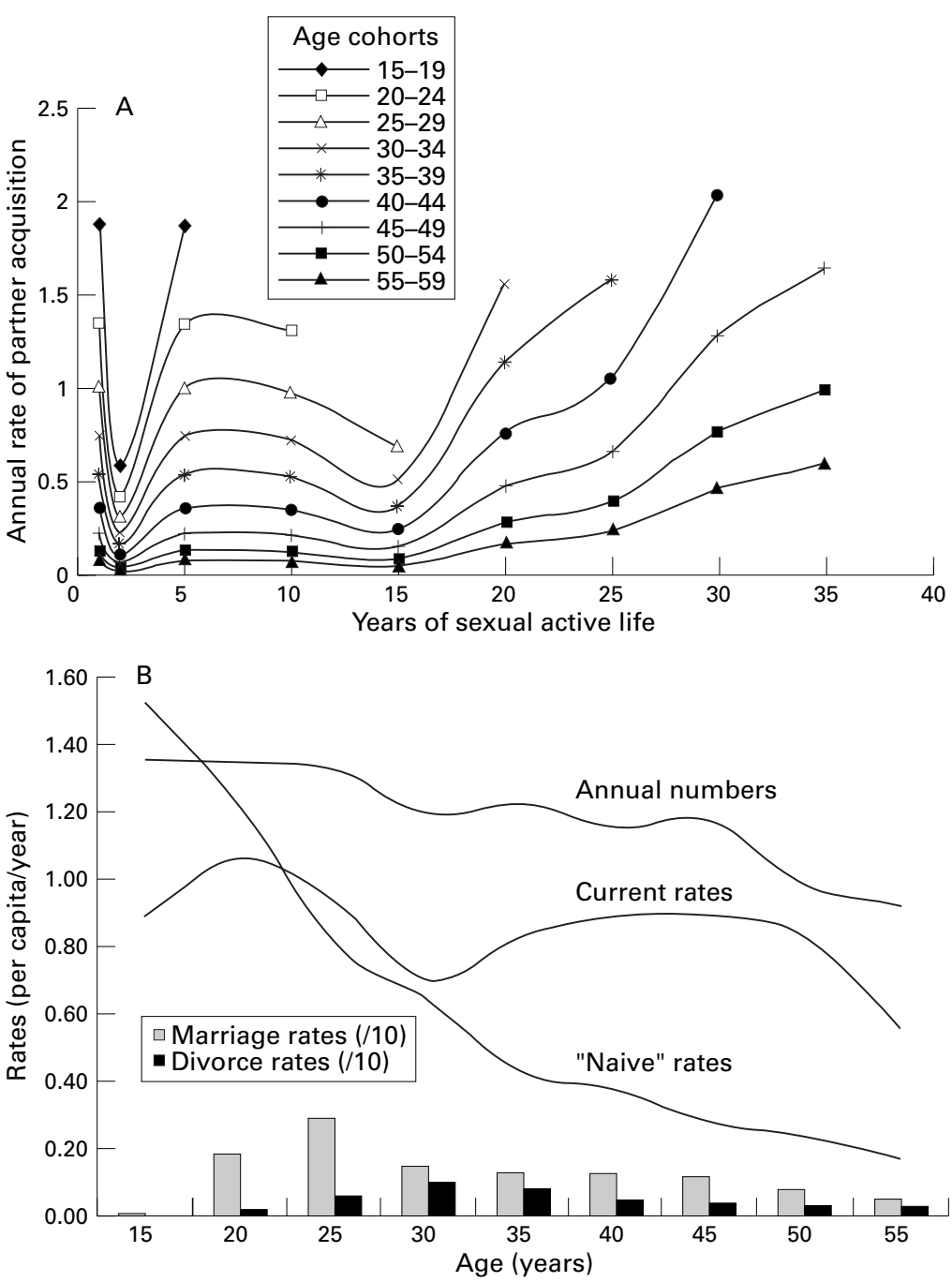

Figure 1 (A) Predicted current annual rates of partner acquisition stratified by age cohorts, as a function of years of sexual activity for the males. Female estimates are 1.6 times lower than male. (B) Comparisons of three average (that is, averaged over the number of years of sexual activity) measures of sexual activity by age (age specific) for the males of Quebec. The age specific annual number of partners is simply the average number of sexual partners reported in the past year for each age group. The age specific "naive" rates ${ }^{6}$ are the average, by age group, of the individuals' number of lifetime sexual partners divided by their number of years of sexual activity. The predicted age specific current rates are the average $\hat{R}_{k i j}$ by age, based on the estimates as described in the Methods section. Trends are similar for females but averages are between 1.5-1.8 times inferior to males. Annual rates of marriage and divorces (per 10 individuals) are also presented (data taken from $E$ Asseli et al, Québec Statistique 1995;819).

the annual "naive" and current rates of partner acquisition for males. Contrary to the current rate function, both the number of partners and the naive rates are monotonic decreasing functions of age. Current rates increase from age $15-20$, followed by a 10 year decrease. At age 30 , the rates increase for another 15 years before falling again. Interestingly, the increase in marriages in Quebec between ages 20-30 coincides with the drop in current rates while the increase after age 30 corresponds to an increase in divorces and deaths. Independently of other risk behaviours, the annual number and naive rates suggest decreasing risks of STD/HIV infection with age while current rates point to $15-20$ years and middle aged (40-50 years) adults as being particularly at risk.

As reflected by the weak correlation between current rates and annual numbers $\left(r_{\text {Spear }}\right.$ $\left.\operatorname{man}_{1}=0.01\right)$ and between current and naive rates $\left(r_{\text {Spearman }}=0.14\right)$, these measures convey different information. The number of partners per time unit and the naive rates contain information on new (formed within the current time unit) and old (formed before the current time unit and that have not yet dissolved) relationships and may be more representative of the prevalence of infection. The current rates of partner acquisition contain information on new partnerships which may be a better predictor of the incidence and individual risk of infections. No incidence or prevalence data were available to evaluate the predictive potential of these different measures. This should be done for bacterial versus viral STDs, in areas of high and low prevalence, for different time unit also taking into account information on local networks and concurrent partnerships.

\section{Discussion}

Given that the bulk of STD cases are observed in the 15-30 age groups, ${ }^{10}$ our results on current rates may appear surprising if one ignores other risk factors. For example, the age mixing pattern, which is assortative by age, ${ }^{10}$ may partly explain these trends. Although less frequently reported by older individuals, condoms may be used more adequately (in terms of how, with whom, and when?). For example, contacts with prostitutes are more often reported by older men but condom use with these partners is also very high. ${ }^{7}$ STD seeking treatment behaviour could also vary with age if older adults with symptoms consult sooner. Our estimates may also be biased since random samples often miss out elusive populations. In our sample, as few as one individual reported having more than 50 partners in the past year! Many reported STD cases could therefore belong to the high activity groups which may have been undersampled in our study. Based on large sexual activity categories, certain subtleties of the data may also be hidden. Moreover, in our sample, only $44 \%$ of the 15-20 year old reported being sexually active compared with $46 \%$ and $69 \%$ in other studies. ${ }^{11}$ If higher risk individuals were ill represented in our sample, became sexually active earlier, and were not proportionally distributed by age, sexual activity duration could be underestimated and the shape of the current rate function with age altered. Finally, case notification data may also be incomplete since they are not fully representative of incident cases.

None the less, these results provide useful information for prevention. It is important to target individuals around sexual debut since the first year of sexual activity is the most active one independent of age. Despite controversies surrounding sex education at primary or secondary school, such education is indeed justified and needs to be intensified especially that the mediatisation on the efficacy of antiviral therapies could compromise these gains. ${ }^{7}$ The attention should extend to older heterosexuals (>35) who use condoms less frequently and have been neglected.

Quebec sexual behaviour shares more features with the United States ${ }^{12}$ population than the British in that the heterogeneity in sexual 
activity is greater, indicating an increased potential for STD propagation. ${ }^{11}$ How big this potential is will remain unknown until we better characterise the tail of the sexual activity distribution as well as STD prevalence rates. ${ }^{11}$

To help us, data on the number of new partners per time unit and relationship durations should be collected/reported as a discrete variable (or fine categories) to preserve the information in the tail of the distribution. The number of partners per time unit could be used as complementary information. This will not solve the discrepancy between the males and females but it would improve mean and variance estimates and the fit of probability distributions which is important to assess the risk of establishment, spread, and persistence and to explain epidemiological patterns of STD/HIV. Data on mixing patterns and concurrent partnerships are also urgently needed but pose other methodological problems.

The authors thanks the Laboratory Center for Disease Control in Canada for financial support. MCB is a research scholar of the National Health Research and Development Program of Health Canada.

Contributors: The study was conceived by Dr Boily; Drs Adrien and Léaune developed the survey design and supervised the data collection; the statistical analysis and interpretation of the data were performed by $M$ Brisson under the supervision of Dr Masse; the first draft of the paper was prepared by M Brisson and subsequent revisions by M Brisson and Dr Boily.

1 Johnson AM, Wadsworth J, Wellings K, et al. Sexual lifestyles and HIV risk. Nature 1992;360:410-12.

2 Laumann EO, Gagnon JH, Michael RT, et al. The social organisation of sexuality: sexual practices in the United States. London: University of Chicago Press, 1994:718

3 ACSF Investigators. AIDS and sexual behaviour in France. Nature 1992;360:407-9.

4 Wadsworth J, Johnson AM, Wellings $\mathrm{K}$, et al. What's in a mean? - an examination of the inconsistency between men and women in reporting sexual partnerships. $7 R$ Statist $S o c$ A 1996;159:111-23.

5 Morris $M$. Telling tails explain the discrepancy in sexual partner reports. Nature 1993;365:437-40.

6 Morris M, Podhisita C, Waver MJ, et al. Bridge populations Morris M, Podhisita C, Waver MJ, et al. Bridge populations
in the spread of HIV/AIDS in Thailand. AIDS 1996;10: in the sprea

7 Adrien A, Dassa C, Leaune V. Les québécois face au sida: Attitudes envers les personnes vivant avec le VIH et gestions des risques. Direction de la santé publique de Montréal-centre, 1998:127.

8 Fleiss JL. Statistical methods for rates and proportions. New York: John Wiley, 1981:58-60.

Kault D. The shape of the distribution of the number of sexual partners. Stat Med 1996;15:221-30.

10 Boily MC, Brisson M, Fournier A. Modélisation mathématique de l'infection VIH-1 dans la population hétérosexuelle de Montréal-Centre. Rapport présenté au Centre Québécois de coordination sur le sida, 1 Décembre 1998.

11 Otis J. Comportements et déterminants des comportements liés à la prévention des MTS et de l'infection au VIH chez les jeunes québécois(e)s: état des connaissances. Rapport présenté à la quebecois(e) s: état des connaissances. Rapport presente a la Direction de l'évaluation, Ministère de la san
ices sociaux, Montréal, 27 Octobre 1995.

12 Michael RT, Wadsworth J, Feinleib J, et al. Private sexual Michael RT, Wadsworth J, Feinleib J, et al. Private sexual
behavior, public opinion, and public health policy related to sexually transmitted diseases: a US-British comparison. Am $\mathcal{F}$ Public Health 1998;88:749-54. 